\title{
Pattern of head injuries in the recent Megaearthquakes in Nepal: an audit to prepare for future!
}

Renu Vaidhya , Archana Joshi, Karjome Lama ,Bidur KC , Bikram Shakya, Amit Thapa

Department of Neurological Surgery, Kathmandu Medical College

Teaching Hospital, Sinamangal, Kathmandu

Correspondence : Dr Amit Thapa, Associate Professor, Department of Neurological Surgery, Kathmandu Medical College Teaching Hospital, Sinamangal, Kathmandu email: dramitthapa@yahoo.com

\begin{abstract}
Introduction and Objective: Nepal falls in very high risk zone for earthquakes. Recently in April 2015, we witnessed the worst human casualty of this century. We present an audit of the head injuries we received at KMCTH during the Mega-earthquake.
\end{abstract}

Materials and Methods: We did an audit of the activities of the department of neurological surgery at KMCTH, during the megaearthquake to identify the pattern of head injuries and make disaster plan for future.

Results: We served more than 150 patients in the emergency who approached with head injuries. Majority were concussion with scalp lacerations and after few hours of observations were discharged. However 34 required surgical intervention with 22 being craniotomies for skull base repair and contusions. Strokes also presented during this period possibly due to emotional stress of the happenings. We suffered a double whammy of internal and external disaster as the staff were also threatened and repeated tremors make it difficult to boost the morale and confidence of the service providers. We drafted a disaster protocol for our department in liaison with the hospital and did table top rehearsals for the same.

Conclusion: A change in pattern of neurotrauma was seen during the Mega-earthquake. The health facility suffered both internal and external disaster. Better preparedness and protocol based approach with coordination at national level would help us to prepare for future.

Key words: disaster planning. mega-earthquake, neurotrauma, stroke 